\title{
Use of SeedCounter Mobile App for Wild Species Seed Number Determination: A Preliminary Study
}

\author{
Farid Kuswantoro * \\ Bali Botanic Garden, Research Center for Plant Conservation and Botanic Gardens, Indonesian Institute of \\ Sciences, Bali 82191, Indonesia
}

*Corresponding au-

thor:

E-mail:

faridkuswan-

toro@ymail.com

\begin{abstract}
Although its simple nature, seed counting is a crucial but demanding process in seed research and conservation. Manual seed counting, which usually takes a lot of effort and time, needs to be supplemented by new, easy-to-use, and accurate tools to simplify the process. Fortunately, the advance of information technology in recent years is significantly easing daily human life, including seed conservation and research. SeedCounter (https://cutt.ly/xhZFMZk) is a smartphone app which could help seed scientist to perform their seed counting process. However, as wild plant seeds come in various sizes, forms, and shapes, the app's ability to perform seed count of wild plant seeds need to be understood entirely. Thus, this study aims to understand the SeedCounter app's ability to perform seed counting in 20 wild plant seeds collected in Bali Botanic Garden Seed Bank Laboratory. We hope that the study will provide preliminary data for the app's potential to help seed conservation and research future efforts. SeedCounter app is downloaded and installed in a Nokia 6.1 Plus smartphone. Seeds photographed using the app with three replications conducted for each of the species. Seed counting is defined as a success if the app can count the seed number three consecutive times correctly. Data analysis was conducted descriptively. The study result showed that the SeedCounter app could correctly count seeds of ten plant species, which compares with $50 \%$ of the tested species. The result highlights SeedCounter's potential to simplified the counting process of some wild plant species seed.
\end{abstract}

Keywords: Android, application, seed, smartphone

\section{Introduction}

Seed counting is a fundamental process in seed research and conservation. In seed conservation, for example, Millennium Seed Bank Partnership Kew's Germination testing: procedure and evaluation stated that seed number determination of collected seed is the base of whether the seed population is appropriate for germination test as well as its test size (Davies et al., 2015). Meanwhile, in seed research, Germination Percentage (GP) is one of the most used germination parameters. In this parameter calculation, the initial seed number is essential as the dividing factor as GP formula is the number of germinated seed divided by the initial seed number and multiplied by a hundred percent (Kader, 2005).

Despite its importance, manual seed number determination is an inconvenience, while although more convenience, electronic counting device is costly (Liu et al., 2017). The expensiveness of electronic counting devices to simplify the seed number determination process is already experienced firsthand by Bali Botanic Garden Seed Bank as an electronic counting device cost up to twelve million Indonesian rupiahs. The device is also still limited in terms of its counting capability as it is not able to count seed that has a bigger or much smaller size than its aperture. As the machine needs constant electricity input to operate, the machine is limited in terms of its practicality, primarily to be used in the field. Thus, to enhance the seed research and conservation effort, another way to simplify the seed number determination need to be found.

In recent years, the booming of the smartphone has impacted almost every aspect of human life. The smartphone's ability to change people's daily life is due to the device mobile nature. This mobile nature is also supported by the development of many mobile applications (apps) that able 
to help people in their daily life. For example, a smartphone app can improve accident detection and remedy (Patel, 2013). Not only for social service, a smartphone digital calendar app name RemindMe is also able to help the senior resident to perform more daily activities (Baric et al., 2019).

The impact of the smartphone is also felt in biological conservation and research. The emergence of plant conservation-related apps such as iNaturalist, for example, can enhance herbarium collection research value (Heberling \& Isaac, 2018). Some smartphone apps are also able to help plant conservationist and researcher to perform a specific task in their work process. An example of this is found in a mobile app named ColectoR, which able to simplify data processing of plant voucher specimens collection (Maya-Lastra, 2016). Not only for voucher specimens collection, android mobile app application named "Field Book" is also developed to simplify plant breeding data management (Rife \& Poland, 2014).

The smartphone which is usually also equipped with a camera is also able to perform image analysis which able to simplify the measurement process of plant leaf area using a mobile app named Easy Leaf Area (Easlon \& Bloom, 2014). The image analysis capability of a smartphone is also able to be used grain phenotyping used SeedCounter mobile app (Komyshev et al., 2017). Not only SeedCounter, Android smartphone-based grain counting, and software is also developed by Liu et al. (2017). These findings highlight the trend of using a mobile device to simplify plantrelated works, including seeds or grain counting.

In their evaluation of the SeedCounter mobile app, Komyshev et al. (2017) suggest that wheat grain number determination using this app resulted in a very low error value of about $1 \%$ mean absolute error and $2 \%$ mean absolute percentage error. Another study that utilized image analysis for grain counting is performed in rice by Gong et al. (2018). These research results highlight the possibility to utilized image analysis, which nowadays can perform by smartphone to perform seed number determination of wild plant species. However, as wild plant species come in various sizes, shapes and forms, a study of the mobile app capability to perform seed counting in these plant seed need to be conducted. Thus, we propose this study as a first attempt to evaluate the potential of SeedCounter to perform seed number determination of wild plant species. The mobile app is interesting for us as it is freely available and relatively easy to use. We hope that this study will provide preliminary data about the potential use of mobile apps, especially SeedCounter, to simplify future seed research and conservation effort.

\section{Material and Methods Study site}

in Bali Botanic Garden Seed Bank Laboratory. The laboratory lighting condition during the data collection is about 216-256 lux. The lighting condition is vital to record as Komyshev et al. (2017) suggest that the lighting condition significantly influences the mobile app's accuracy.

\section{Study material}

In this study SeedCounter, mobile app version 2.1.4 was downloaded from Google Play Store and installed in a Nokia 6.1 Plus smartphone. A white A4 paper sheet was used as the background and seeds of twenty wild plant species seed collected by the Bali Botanic Garden Seed Bank Laboratory were used as the study object (Table 1). The used seeds are comprising of the display seed, active collection seeds, and seeds that still in the drying process. Thus, the used seed may not currently present on the Seed Bank active collection database. These species were purposively selected to represent the diversity of wild plant species seed morphology. However, we did not use microscopic seeds such as orchids and begonias seeds as the seeds are too small to be observed using the smartphone camera. 


\section{Study procedure}

For each wild plant species, up to twenty-five seeds were counted manually before used for seed number determination using SeedCounter mobile app. During this study, the app default setting was used in seed number determination. The seeds were then placed on a white A4 paper sheet following Komyshev, Genaev \& Afonnikov (2017) which suggest that no seed should touch others seed to other seed to avoid counting error. Seeds picture then taken using SeedCounter mobile app. Three replications were conducted for each plant species. The number of the app correct and wrong seed number determination noted, and pictures of the counting process saved.

Table 1. Wild plant species seeds name and number used during this study

\begin{tabular}{|c|c|}
\hline Plant Species & Seeds Number \\
\hline \multicolumn{2}{|l|}{ Apocynaceae } \\
\hline Rauvolfia caffra Sond. & 25 \\
\hline Wrightia pubescens R.Br. & 25 \\
\hline \multicolumn{2}{|l|}{ Arecaceae } \\
\hline Areca vestiaria Giseke & 25 \\
\hline Corypha utan Lam. & 25 \\
\hline \multicolumn{2}{|l|}{ Asparagaceae } \\
\hline Agave attenuata Salm-Dyck & 25 \\
\hline \multicolumn{2}{|l|}{ Cupressaceae } \\
\hline Hesperocyparis lusitanica (Mill.) Bartel & 25 \\
\hline \multicolumn{2}{|l|}{ Dilleniaceae } \\
\hline Dillenia serrata Thunb. & 25 \\
\hline \multicolumn{2}{|l|}{ Elaeocarpaceae } \\
\hline Elaeocarpus grandiflorus $\mathrm{Sm}$. & 25 \\
\hline \multicolumn{2}{|l|}{ Euphorbiaceae } \\
\hline Acalypha spiciflora Burm.f. & 25 \\
\hline \multicolumn{2}{|l|}{ Fabaceae } \\
\hline Abrus precatorius L. & 25 \\
\hline Biancaea sappan (L.) Tod. & 25 \\
\hline Canavalia rosea (Sw.) DC. & 25 \\
\hline Gleditsia assamica Bor & 25 \\
\hline Guilandina bonduc L. & 24 \\
\hline \multicolumn{2}{|l|}{ Juglandaceae } \\
\hline Engelhardia spicata Lechen ex Blume & 25 \\
\hline \multicolumn{2}{|l|}{ Poaceae } \\
\hline Coix lacryma-jobi L. & 25 \\
\hline \multicolumn{2}{|l|}{ Podocarpaceae } \\
\hline Dacrycarpus imbricatus (Blume) de Laub. & 25 \\
\hline \multicolumn{2}{|l|}{ Primulaceae } \\
\hline Ardisia crenata Sims & 25 \\
\hline \multicolumn{2}{|l|}{ Sapindaceae } \\
\hline Acer laurinum Hassk. & 25 \\
\hline \multicolumn{2}{|l|}{ Theaceae } \\
\hline Schima wallichii (DC.) Korth. & 25 \\
\hline
\end{tabular}




\section{Data analysis}

Seed number determination was considered as success seed number determination if the app were able to correctly count the seed number in all of the tree replication. On the other hand, the seed number determination considered as failed if the mobile app were not able to count seed number in all of the three replications correctly. The acquired data were then descriptively analyzed and presented as pictures and graphs.

\section{Results and Discussion}

During this study, the SeedCounter mobile app was able to determine the seed number of ten wild plant species. This number is comparable with half of the all plant species used in this study (Figure 1.). The plant species and picture of seed with success seed number determination presented in Table 2. At the same time, plant species with failed seed number determination presented in Table 3.

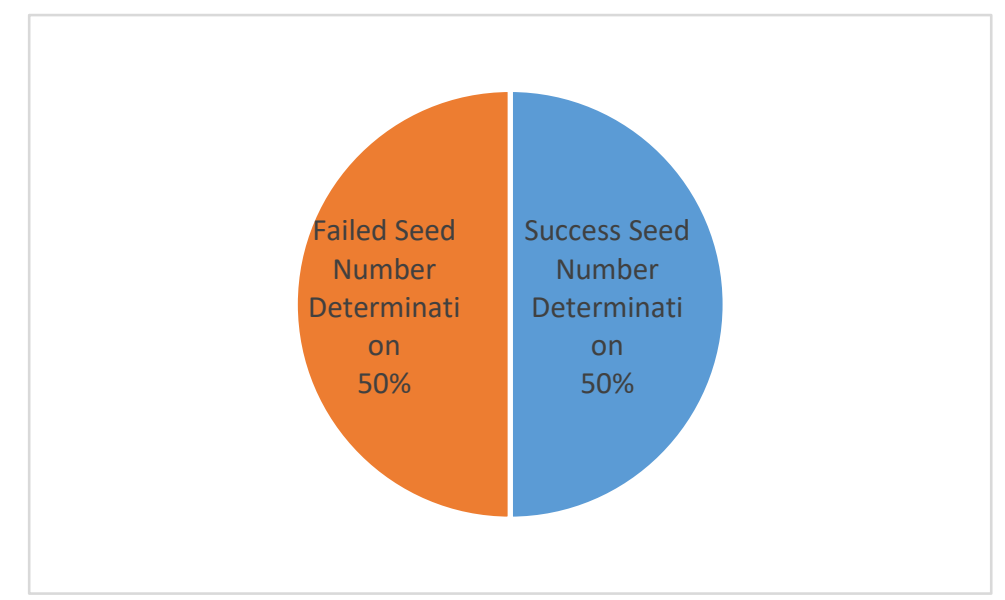

Figure 1. Percentage of plant species with success and failed seed number determination by seedcounter mobile app.

Table 2. Plant Species with Success Seed Number Determination using SeedCounter Mobile App.

\begin{tabular}{|l|c|c|}
\hline \multicolumn{1}{|c|}{ Species Name } & Pictures \\
\hline Wrightia pubescens R.Br. & & \\
\hline Rauvolfia caffra Sond. & & \\
\hline
\end{tabular}




\begin{tabular}{|c|c|}
\hline $\begin{array}{l}\text { Hesperocyparis lusitanica } \\
\text { (Mill.) Bartel }\end{array}$ & $=0$ \\
\hline Dillenia serrata Thunb. & \\
\hline Acalypha spiciflora Burm.f. & 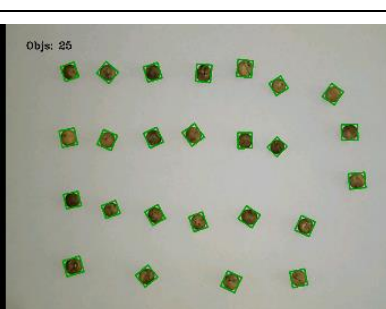 \\
\hline Abrus precatorius L. & \\
\hline Gleditsia assamica Bor & 0 \\
\hline $\begin{array}{l}\text { Dacrycarpus imbricatus } \\
\text { (Blume) de Laub. }\end{array}$ & obs: 25 \\
\hline To be continued & \\
\hline
\end{tabular}




\begin{tabular}{|l|l|l|l|}
\hline Ardisia crenata Sims & & & \\
& & & \\
\hline
\end{tabular}

Table 3. Plant species with failed seed number determination using SeedCounter mobile app

\begin{tabular}{|l|c|c|c|}
\hline \multicolumn{1}{|c|}{ Species Name } & & Pictures \\
\hline Slaeocarpus grandiflorus & & & \\
\hline
\end{tabular}




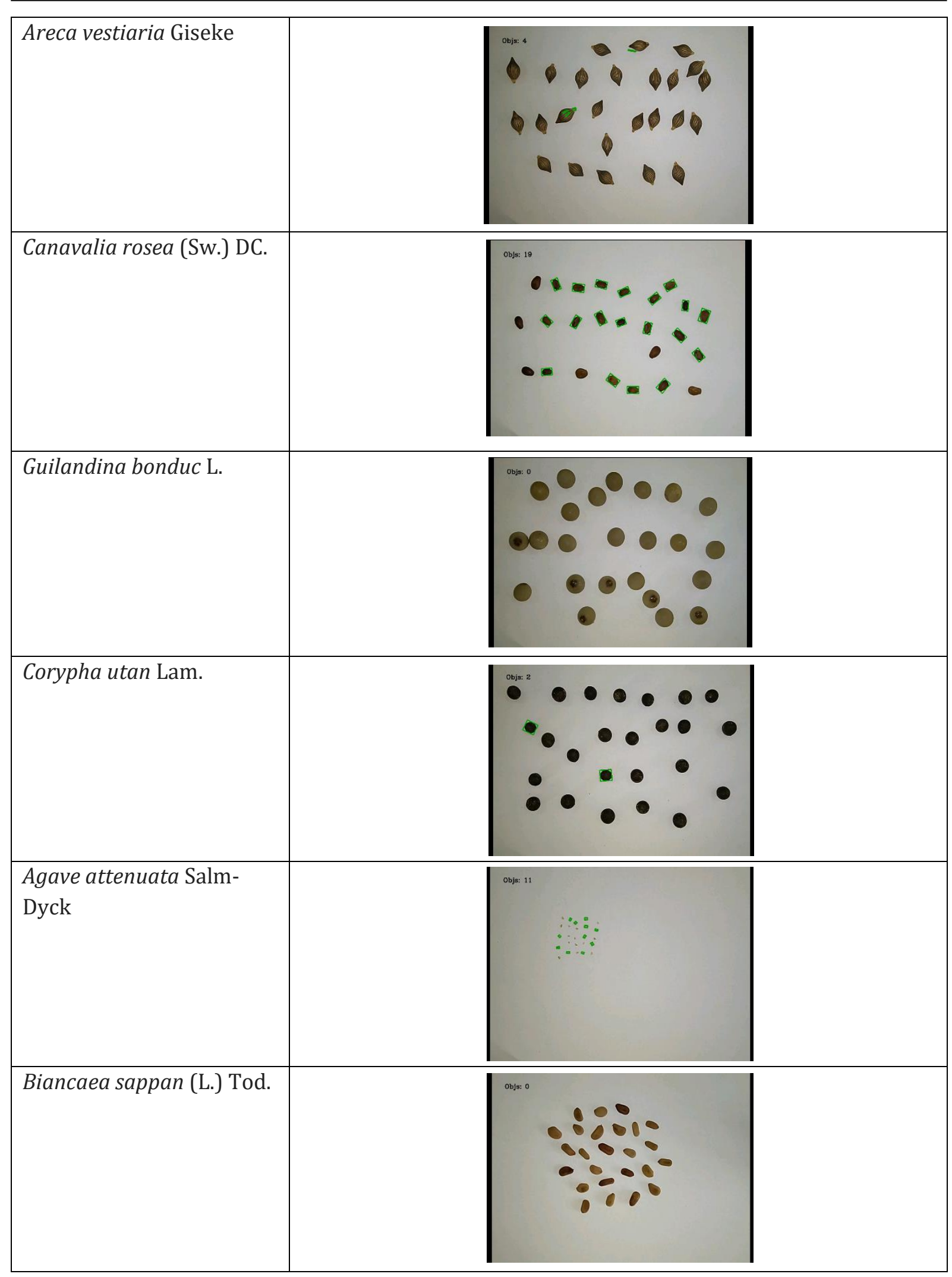

This study result showed that seeds with successful and unsuccessful seed number determination come from various shapes. The spherical seeds such as A. precatorius D. imbricatus and $A$. 
crenata showed successful seed number determination while other spherical seeds such as G. bon$d u c$ and $C$. utan showed unsuccessful seed number determination. Meanwhile, the unsymmetric seed shape of $D$. serrata and A. attenuata are producing successful and unsuccessful seed number determination results. These results point out that seed shape seems to not correlate with the app's capability to perform seed number determination.

Seed size also seems not affected SeedCounter mobile app's capability to determine seed number. Although the app failed to determine a small $A$. attenuate seed number, the app can successfully determine the $H$. lusitanica seed number, which has a comparable size with $A$. attenuate. The mobile app was able to successfully counting $G$. assamica seed numbers but failed to count the seed number of $C$. rosea and B. sappan which have comparable seed sizes and shape to G. assamica.

This study result showed one reason that probably contributes to the mobile app's inability to perform successful seed number determination is due to the app image analysis failed to detect the seeds correctly. As the app is based on image analysis, failure in this process will indeed affect the app's ability to perform seed counting. The image analysis failure made the app unable to differentiate the seeds and the non-seed in the picture. In E. grandiflorus seed number determination, for example, the app is mistakenly counting E. grandiflorus seed coat spines instead of the seed itself. Thus, it made the seed number determination result much higher than the actual seed number. The same mistake is also observed in seed number determination of E. spicata, A. laurinum, $C$. lacryma-jobi, and A. vestiaria.

Another image analysis-related error that probably contributes to the app's failure to perform seed counting is the app's inability to detect seeds in the picture. During this study, this kind of error made the app only counting some tested seeds and ignore other seeds in the picture such as observed in seed number determination of $C$. rosea, $C$. utan, and $A$. attenuate. Meanwhile, in seed number determination of $G$. bonduc and B. sappan the app is entirely unable to detect the seeds.

Based on this study result, SeedCounter mobile app proved to have the potential to simplify the seed number determination of wild plant species. However, as this study is still minimal, it is not able to fully understand the potential of the mobile app to simplify the seed counting process. Nevertheless, this study can provide preliminary data for the opportunity of using a mobile app, especially SeedCounter to perform wild plant species seed counting. Thus, further research with more diverse seed morphology and study condition to fully understand this app effectiveness for wild plant species seed counting. Further research in image analysis algorithm may also be conducted as research and finding in this subject is still continuously happening, such as the one conducted by Neilsen et al. (2017).

\section{Conclusion}

The SeedCounter mobile app can perform the seed determination number of ten wild plant species seeds. This number is comparable with $50 \%$ of all tested plant species. Error in image analysis probably the reason for the app's inability to perform successful seed number determination. Further study needs to be conducted to fully understand the mobile app's effectiveness to perform counting of wild plant species seed. However, this study result showed that SeedCounter mobile app is the potential to be used to simplify the seed counting process of some wild plant species seed.

\section{Acknowledgment}

The author conveys their gratitude to Gusti Made Candiwati and Putri Kesuma Wardhani for the support during the data collection process. We would also like to thanks all people that help the author during the manuscript writing process. 


\section{References}

Baric, V., Andreassen, M., Öhman, A., \& Hemmingsson, H. (2019). Using an interactive digital calendar with mobile phone reminders by senior people-a focus group study. BMC geriatrics, 19(1), 1-11.

Davies, R., Di Sacco, A., \& Newton, R. (2015). Germination testing: procedures and evaluation. Technical Information Sheet_13a. Royal Botanic Gardens, Kew.

Easlon, H. M., \& Bloom, A. J. (2014). Easy Leaf Area: Automated digital image analysis for rapid and accurate measurement of leaf area. Applications in plant sciences, 2(7), 1400033.

Gong, L., Lin, K., Wang, T., Liu, C., Yuan, Z., Zhang, D., \& Hong, J. (2018). Image-Based on-panicle rice [Oryza sativa L.] grain counting with a prior edge wavelet correction model. Agronomy, 8(6), 91.

Heberling, J. M., \& Isaac, B. L. (2018). iN aturalist as a tool to expand the research value of museum specimens. Applications in Plant Sciences, 6(11), e01193.

Kader, M. A. (2005). A comparison of seed germination calculation formulae and the associated interpretation of resulting data. Journal and Proceeding of the Royal Society of New South Wales, 138, 65-75.

Komyshev, E., Genaev, M., \& Afonnikov, D. (2017). Evaluation of the SeedCounter, a mobile application for grain phenotyping. Frontiers in plant science, 7, 1990.

Liu, T., Chen, W., Wang, Y., Wu, W., Sun, C., Ding, J., \& Guo, W. (2017). Rice and wheat grain counting method and software development based on Android system. Computers and Electronics in Agriculture, 141, 302-309.

Maya-Lastra, C. A. (2016). ColectoR, a digital field notebook for voucher specimen collection for smartphones. Applications in Plant Sciences, 4(7), 1600035.

Neilsen, M. L., Courtney, C., Amaravadi, S., Xiong, Z., Poland, J., \& Rife, T. (2017, October). A dynamic, real-time algorithm for seed counting. In Proc. Of the 26th International Conference on Software Engineering and Data Engineering.

Patel, K. (2013). Utilizing the Emergence of Android Smartphones for Public Welfare by Providing Advance Accident Detection and Remedy by 108 Ambulances. International Journal English Research Technology (IJERT), 2, 1340-1342.

Rife, T. W., \& Poland, J. A. (2014). Field book: an open-source application for field data collection on android. Crop Science, 54(4), 16241627 